such treatment to be delivered in the patient's home.

Finally, we should remember that for each uncooperative patient there is likely to be an over-compliant one. Quietly tolerating adverse effects from over zealous drug regimens, they may believe that 'the doctor knows best' or indeed be unaware that they are free to refuse treatment (Eastwood \& Pugh, 1997).

EASTWOOD, N. \& PUGH, R. (1997) Long-term medication in depot clinics and patients' rights: an issue for assertive outreach. Psychiatric Bulletin, 21, 273-275.

GoldSTEIN, M. J. (1992) Psychosocial strategies for maximising the effects of psychotropic medications for schizophrenia and mood disorders. Psychopharmacology Bulletin, 28, 237-240.

Sensky, T., Hughes, T. \& HiRsch, S. (1991) Compulsory psychiatric treatment in the community. I. A controlled study of compulsory community treatment of patients under the Mental Health Act: special characteristics of patients treated and impact of treatment. British Joumal of Psychiatry. 158. 792-799.

ElizaBeTH H. HARE, Specialist Registrar, East and Mid Lothian Trust, Herdmanflat Hospital, Aberlady Road, Haddington EH41 3BU

\section{Care Programme Approach: equivalent developments in Australia}

Sir: The Care Programme Approach (CPA) has clearly generated a significant amount of controversy in Britain. The Victorian Government (Australia) has published a series of policy documents (Psychiatric Services Division, 1994) which have created expectations that a case management model of care, similar to the CPA system, will be provided by all public psychiatric services. The recommended model includes formal intake, the appointment of a case manager, team review, individual service planning and case closure for all patients treated. This model is being gradually adopted statewide as funding agreements demand.

The Geelong psychiatric services embarked on adopting this case management model in 1994. As discussed by Ferguson (1996), we found these attempts, without an integrated patient information system, laborious, frustrating to monitor and greeted with considerable resistance.

Over the past three years we have designed new patient record documents corresponding to each of the processes in the case management model and a computerised mental health patient information management system (MH-PIMS), on which is recorded some basic data on each patient and allows each patient to be tracked through the system until case closure. MH-PIMS produces reports on a weekly basis, which are of value to teams in conducting their everyday business and review meetings. This includes lists of patients due for review; patients discharged from the in-patient unit in the previous month and case-load lists.

In the year ending October 1997, the average active case-load of case managers was 25; each case manager took on an average of 23 new cases and discharged 22.5 cases in the same period. This throughput was maintained by adhering to the case management model and monitoring this in individual supervision and in team meetings.

Although the introduction of this structured system has been demanding on management and challenging to clinicians, our staff now have a positive attitude towards the system and we believe our perseverance has yielded results.

Ferguson, B. (1996) Principles of computers in care management and the care programme approach British Journal of Hospital Medicine, 56, 466-469.

PSYCHIATRIC SERVICES DIVISION (1994) Victoria's Mental Health Service, The Framework for Service Delivery. Victoria: Department of Health and Community Services, Victorian Government.

T. Callaly, Chief of Service, Geelong Hospital, Division of Psychiatry, Swanston Centre, Cnr Myers and Swanston Street, Geelong, Victoria, Australia

\section{Need for local policies on Section 135 of the Mental Health Act 1983}

Sir: There are important differences in the provisions of Sections 135(1) and 135(2) of the Mental Health Act 1983. Section 135(1) applies to people who are not yet admitted to psychiatric facilities. In this case, an approved social worker applies for the warrant, and the named constable to whom it is addressed must be accompanied, in the execution of the warrant, by an approved social worker and a registered medical practitioner. All very clear.

Section 135(2), on the other hand, applies to detained patients who are absent from hospital without due authority. In this case, any constable, or any other person authorised under the Mental Health Act 1983 or under Section 83 of the Mental Health (Scotland) Act 1960 to take or retake a patient may apply for the warrant. In the execution of the warrant, it is not mandatory that the constable must be accompanied by anyone: he or she may be accompanied by a registered medical practitioner, or by any person authorised, under the Act, to take or retake a patient.

Those authorised, under Section 18 of the Mental Health Act 1983, to take or retake a patient, are: an approved social worker, an officer on the staff of the hospital (including nurses and doctors), any constable and any person(s) authorised in writing by the managers 